\title{
A review of social disinhibition after traumatic brain injury
}

Word count: 6763 (excluding title page, abstract, references)

\section{$\underline{1}^{\text {st }}$ Author (corresponding)}

Katherine Osborne-Crowley

School of Psychology,

The University of New South Wales, New South Wales, 2052, Australia

Email: k.osbornecrowley@unsw.edu.au

Phone: +61293853590

$\underline{2^{\text {nd }} \text { Author }}$

Skye McDonald

School of Psychology,

The University of New South Wales, New South Wales, 2052, Australia

Email: s.mcdonald@unsw.edu.au

Osborne-Crowley, K. \& McDonald, S. (2016). A review of social disinhibition after traumatic brain injury. Journal of Neuropsychology, DOI: 10.1111/jnp.12113 
1

\section{Abstract}

Acquired social disinhibition refers to a debilitating behavioural syndrome commonly reported after a severe traumatic brain injury (TBI) and is characterised by inappropriate social behaviour, often described as immaturity and insensitivity towards others. These behaviours can have enduring effects on the social capability of the individual and their relationships with others. However, research into socially disinhibited behaviour after TBI has been thwarted by a lack of consensus in the literature on definition and measurement.

This review provides an overview of our current understanding of the definition, measurement, prevalence, associated outcomes, neuropathology and underlying mechanisms of social disinhibition after TBI. In addition, suggestions are made for future research to further our understanding of this syndrome with the eventual aim of rehabilitating problematic behaviours. It is concluded that an improved understanding of what causes disinhibited behaviour after TBI will be necessary for the development of effective treatment strategies aimed at the rehabilitation of underlying impairments. 
Traumatic brain injury (TBI) refers to an injury to the brain caused by an external

force and most commonly results from motor vehicle accidents, falls and assaults. These injuries disproportionately affect young males under 25 years of age as well as individuals older than 65 years (Langlois, Rutland-Brown, \& Wald, 2006). It has been estimated that TBI affects 10 million people worldwide each year (Hyder, Wunderlich, Puvanachandra, Gururaj, \& Kobusingye, 2007), making it an important international public health concern (Lin et al., 2010). While most of these injuries are mild in nature (Zaloshnja, Miller, Langlois, \& Selassie, 2008), severe TBI is associated with enormous direct and indirect costs for the community and major disability for the individual (Narayan et al., 2002). In more severe injuries, acceleration-deceleration forces on the brain result in multifocal lesions throughout the cerebrum, concentrated in the frontal and temporal lobes, as well as attendant white matter shearing (Bigler \& Maxwell, 2013).

Problems with social functioning are commonly experienced after such injuries and are frequently reported to be more distressing than cognitive or physical disability (Kelly, Brown, Todd, \& Kremer, 2008). One particularly debilitating disturbance to social behaviour which is commonly reported after severe TBI is acquired social disinhibition, a behavioural syndrome characterised by inappropriate social behaviour often described as immaturity and insensitivity towards others. Although there is evidence that disinhibited behaviours are common after TBI, focus in the literature has tended to remain around other common challenging behaviours, such as aggression, perseveration and adynamia (lack of initiation) (Sabaz et al., 2014). Research into social disinhibition after TBI has been thwarted by a lack of consensus in the literature on definition and measurement. The aim of this paper is to review the research to date that has reported on social disinhibition after TBI, to provide an overview of our current understanding of its definition, measurement, prevalence, associated 
outcomes, neuropathology and underlying mechanisms with a view towards directions for remediation.

\section{Definition}

There is currently no consensual definition regarding social disinhibition in the TBI literature. Disinhibition is often considered to be the inability to supress an action or verbalisation when it is inappropriate to the current environmental contingencies (HannaPladdy, 2007; Rieger \& Gauggel, 2002). However, numerous other terms are also used to refer to these sorts of behaviours, including impulsivity, dyscontrol and dysregulation (Kocka \& Gagnon, 2014). In an effort to delineate the constructs of disinhibition and impulsivity as they are used in the TBI literature, Kocka and Gagnon (2014) concluded that impulsivity refers to a set of behavioural tendencies, and that disinhibition reflects the cognitive processes underlying these behaviours. Although this delineation is useful theoretically, it should be noted that these terms are largely used interchangeably in the literature. The definition provided by Arciniegas and Wortzel (2014) that social disinhibition is "socially inappropriate verbal, physical or sexual acts which reflect a loss of inhibition or an inability to conform to social or cultural behavioural norms" (p. 32) encompasses both behaviour and cognition. We propose, therefore, that this be adopted as a working definition in the TBI literature.

The socially disinhibited behaviours after TBI described in the literature are diverse and potentially multi-determined. In order to get a more precise picture of what social disinhibition entails, a taxonomy of "disinhibited behaviours" and their co-occurrence is needed. As a starting point, despite the broad definition of disinhibition that we have adopted, disinhibited behaviours tend to be either physical actions (intimate/sexual advances and acting impulsively) or verbal behaviours. Verbal behaviours described in the literature appear to fall into three domains: (1) insertion of poorly considered utterances including insensitive remarks, overly intimate information, sexual references and swear words (2) failure to adhere 
to the rules of discourse leading to poor turn-taking, excessive side tracks, off topics and talking too much and (3) speaking from an egocentric perspective, i.e. lacking concern, selfishness, childishness, arguing, not getting along with others. Whether such a taxonomy reflects a real distinction in either disinhibited behaviour or its causes is yet to be researched. Clearly, misplaced aggression is socially inappropriate, and thus might be considered to fall into the social disinhibition category of behaviours. However, aggression is usually considered to be a separate behavioural profile. Future research should seek to determine to what extent aggressive behaviours and other socially inappropriate behaviours co-occur in samples of people with brain injury and thus determine whether they may represent they same underlying construct.

\section{Measurement of disinhibited behaviour}

Valid and reliable measurement of social disinhibition after TBI is important for attaining accurate figures on its prevalence and for determining its predictors and potential underlying mechanisms. Measurement of social disinhibition after TBI, however, has been inconsistent across studies. Typically, studies on social disinhibition in TBI populations have utilised self-report or informant-report measures. These measures have rarely been formulated specifically to detect socially disinhibited behaviours following TBI. More commonly, measures used to assess social disinhibition have been designed to provide an overview of neurobehavioural symptoms following TBI or frontal lobe damage which include, but are not limited to, disinhibited behaviours. Examples include the Current Behaviour Scale (CBS; Elsass \& Kinsella, 1987), the Dysexecutive Questionnaire (DEX; Burgess, Alderman, Evans, Emslie, \& Wilson, 1998), the European Brain Injury Questionnaire (EBIQ; Teasdale et al., 1997), the Frontal Systems Behaviour Scale (FrSBe; Stout, Ready, Grace, Malloy, \& Paulsen, 2003), the Iowa Scales of Personality Change (Barrash, Anderson, Jones, \& Tranel, 1997), the Neuropsychology Behaviour and Affect 
Profile (NBAP; Nelson et al., 1989), Neuropsychiatric Inventory (NPI; Cummings et al., 1994), and the Overt Behaviour Scale (Kelly, Todd, Simpson, Kremer, \& Martin, 2006).

Table 1 outlines these measures and provides details about their psychometric properties.

Table 1 about here.

Of the measures outlined, the disinhibition domain of the NPI represents the most tailored informant report measure of social disinhibition following TBI to date. The disinhibition domain of the NPI assesses a number of behaviours which accurately reflect those described in the literature. Further, the informant is asked to rate the frequency and severity of these behaviours as well as the level of distress these behaviours cause. Although the NPI was designed for use in patients with dementia, three recent studies have demonstrated that it is sensitive to changes in behaviour in populations of individuals with TBI (Cantagallo \& Dimarco, 2002; Ciurli, Formisano, Bivona, Cantagallo, \& Angelelli, 2011; Monsalve, Guitart, Lopez, Vilasar, \& Quemada, 2012). The FrSBe can also be recommended for measuring social disinhibition after TBI since items on the disinhibition subscale also closely match those described in the literature and it has demonstrated sound psychometric properties in TBI samples (Grace, Stout, \& Malloy, 1999). Unlike the NPI, though, the FrSBe doesn't measure the distress levels associated with the disinhibited behaviour.

Despite the fact that both the NPI and the FrSBe are well formulated to assess social disinhibition, the use of informant report to measure these sorts of behavioural problems has been criticised, since it can be influenced by the personality structure or mood state of the informants (Milders, Fuchs, \& Crawford, 2003). Further, these measures may be influenced by a retrospective, or "good-old-days", bias whereby individuals with TBI and their carers may have an overly positive view of pre-injury abilities and thus may endorse an inflated increase in post-injury symptoms. 
As an alternative, observational measures represent a more objective method of quantifying social disinhibition after TBI which are not subject to the biases associated with informant report measures. A number of studies have used observational measures to assess social behaviour in people with TBI. These have tended to focus on impairments in a broad range of social skills and pragmatic language use, which may encompass socially disinhibited behaviours. The Revised Behavioural Referenced Rating System for Intermediate Social Skills (BRISS-R; Farrell, Rabinowitz, Wallander, \& Curran, 1985) is one such measure. The BRISS scales have been used in a number of studies of people with TBI, usually when judging social behaviour when interacting with an opposite-sex stranger. These studies have tended to show that participants with TBI are rated as less appropriate than controls on partner-directed behaviour, including self-centred behaviour and partner involvement (McDonald, Flanagan, Martin, \& Saunders, 2004). In a study using a different set of four scales, 15 minute interactions with a stranger involving participants with TBI were rated as less appropriate, as well as less interesting, less rewarding and more effortful, than conversations involving orthopaedic controls (Bond \& Godfrey, 1997). This preliminary evidence suggests that socially disinhibited behaviour can be detected during social interactions and points to the potential of developing a specific observation rating scale to assess socially disinhibited behaviours after TBI. In fact, Votruba et al. (2008) concluded that behavioural observation is required to identify disinhibition in the presence of global deficits, since neuropsychological tests have poor specificity. With this in mind, the current authors developed a set of ratings scales designed specifically to detect socially disinhibited behaviours after TBI observed in a structured interview with an experimenter. Ratings made on these scales achieved acceptable inter-rater reliability, were able to distinguish a group of individuals with TBI from age-matched controls and were found to be related to informant reported frequency of disinhibited behaviours on the NPI (Author citation). 
Nonetheless, the use of rating scales to assess behaviour is not without drawbacks.

Rating behaviour reliably is notoriously difficult especially for global judgements such as “inappropriate/appropriate”. The BRISS-R scales were developed to overcome such problems by having specific behaviour referents to anchor decisions (e.g. "aggressive opinion", "no self-disclosure"). Inter-rater reliability using the BRISS-R has been good to excellent in some studies (eg. Marsh \& Knight, 1991) but poorer in others (eg. McDonald et al., 2004) despite intensive training of the raters. Rating behaviour in a structured interview (e.g. OsborneCrowley et al., 2015) rather than a free form interaction may be one way to improve this. Another draw-back of observational measures is that they can reflect a conservative estimate of disinhibited behaviours, since only a short period of behaviour is being observed. Thus, they may fail to capture significant disinhibited behaviour which occurs relatively infrequently. Studies to date have tended to utilise either behaviour ratings or an objective behaviour assessment. However, in order to assess disinhibited behaviour objectively, as well as gather information about behavioural patterns over a long period of time, the best approach would be the use of observational measures in conjunction with self- and informant- report measures.

\section{Measurement of response inhibition}

Informant questionnaires and observational rating scales focus upon the behavioural manifestation of social disinhibition. As an alternative, some neuropsychological tests either attempt to measure response inhibition directly, or are sensitive to errors that suggest a failure of inhibition. The Hayling Sentence Completion Test, for example, directly taps inhibition by providing subjects with unfinished sentences and asking them to provide a word that does not complete the sentence. In this way, subjects must inhibit the pre-potent verbal response. A number of studies have shown that patients with behavioural-variant frontotemporal dementia, a neurological disorder characterised by disinhibited behaviour, perform poorly on 
the Hayling Sentence Completion Test (eg. Hornberger, Geng, \& Hodges, 2011; Hornberger, Savage, et al., 2011), suggesting that it may be a good neuropsychological indicator of an organic disinhibition syndrome. There are numerous studies of TBI that also demonstrate poor performance on this task (eg. Draper \& Ponsford, 2008; Senathi-Raja, Ponsford, \& Schonberger, 2010). Rule-break errors on fluency tests have also been taken as an index of inhibition since they represent an inability to inhibit responding with words that are forbidden (eg proper nouns). Further, there are a multitude of other tasks which measure inhibitory control, such as the Go/No-Go test, the Sustained Attention to Response Test (SART), the Continuous Performance Test (CPT) and the Stop-Signal task. Each of these tasks requires participants to respond on some trials while inhibiting responding on others. Thus, errors of commission represent an inability to inhibit responding and have been demonstrated to be sensitive to TBI (Cicerone, 1997; Dimoska-Di Marco, McDonald, Kelly, Tate, \& Johnstone, 2011; Laidlaw, 1993; Tinius, 2003). In fact, Braun, Daigneault, and Champagne (1989) found that, in general, tasks which are designed to elicit errors of commission were very effective in distinguishing people with chronic TBI from controls. Further, in a meta-analysis DimoskaDi Marco et al. (2011) concluded that response inhibition impairments in TBI were not accounted for by processing speed or injury severity, suggesting that poor performance on these tasks exists beyond a backdrop of broader impairment. Not all studies, however, have demonstrated an impairment on these inhibitory control tasks after TBI (Rieger \& Gauggel, 2002). A problem arising with these sorts of paradigms is that it is difficult to determine what underlying mechanism is responsible for errors in task performance. In fact, one study has demonstrated that errors that manifest identically in terms of behaviour can be identified electrophysiologically as either errors of sustained attention or errors of inhibition (O'Connell et al., 2009). 
Although these neuropsychological tests of inhibition have been shown to be sensitive to TBI, there has been only limited research to determine whether they can predict social disinhibition following TBI. Errors on fluency tests in people with TBI have been found to be related to loss of emotional control on the $C B S$ (Tate, 1999) and informant reported disinhibition on the NPI (Osborne-Crowley, McDonald, \& Francis, 2015). However, Osborne-Crowley et al. (2015) found no relationship between errors on a fluency task and social disinhibition observed in the laboratory. A study in children found that frontal white matter damage after TBI was related to both poor inhibition on the Stop-Signal task and everyday inhibition measured by the Behavior Rating Inventory of Executive Function (BREIF) (Lipszyc et al., 2014), indicating that poor performance on the Stop-Signal task may indicate an organic disinhibition syndrome. On the other hand, the Go/No-Go task, has been shown to be unrelated to disinhibition observed in the laboratory after TBI (Votruba et al., 2008). These studies investigating relationships between inhibitory control measures and disinhibition after TBI are summarised in Table 3. Thus, while there is some evidence to suggest that neuropsychological tests of response inhibition may tap into social disinhibition as reported by informants the results are generally variable. This is not entirely unexpected given the very different nature of the measures, objective and proximal on the one hand, subjective and distal on the other. Further, the studies discussed above all have relatively small sample sizes. Future larger-scale research which utilises multiple response inhibition measures and assesses social disinhibition on via both informant-report and objective laboratory observation will be useful in clarifying whether formal inhibition measures are related to disinhibition in social situations.

Table 3 about here.

\section{Prevalence}


The prevalence of social disinhibition after TBI has been difficult to establish due to a

lack of consensus surrounding definition and measurement. In fact, Sabaz et al. (2014) noted

that rates for inappropriate social behaviour are the most difficult to obtain of all the

challenging behaviours after TBI due to a lack of consensus around which behaviours fall

into the category. Early studies investigating the psychosocial sequelae of TBI reported rates

between $30 \%$ and $60 \%$ of behaviours such as childishness, talking too much, behaving in socially embarrassing ways and intrusiveness (Oddy, Coughlan, Tyerman, \& Jenkins, 1985; excessive talking (26\% to $33 \%$ across three time points) and childishness ( 35 to $46 \%$ across three time points). Further, McKinlay et al. (1981) noted that changes in behaviour often increased over the first 12 months post injury. A longitudinal study by Lezak and O'Brien (1988) showed that a number of social behaviour items on the Portland Adaptability Inventory (PAI), including inappropriate social interaction, continued as significant problems for more than one third of the patients tested through to five years post-injury. due to the explicit adoption of terms such as 'socially inappropriate behaviour' or 'disinhibition'. In one study, for instance, more than a quarter of the sample of 175 participants at two year post-injury self-reported inappropriate social behaviour (Ponsford, whether multiple profiles best characterise the emotional behavioural sequelae of adults with TBI and found that $13 \%$ of their sample of 300 individuals formed an 'externalising subtype' characterised by social maladjustment, nonconformity, difficulties with impulsivity and exercising judgement and problems regulating behaviours and establishing connections with 
others. Three studies which employed the Neuropsychiatric Inventory (NPI) found rates of $22 \%, 28 \%$ and $32 \%$ of disinhibition in severe TBI populations respectively (Cantagallo \& Dimarco, 2002; Ciurli et al., 2011; Monsalve et al., 2012). The most frequent symptoms reported were acting impulsively, speaking confidently with unfamiliar people and being tactless and offensive. Johnson and Balleny (1996) reported that among a group of 18 patients with severe TBI more than 18 months post-injury, relatives indicated that $78 \%$ showed behavioural difficulties at home and $44 \%$ were described as disinhibited. In a sample of 190 participants with ABI who had been referred to a behaviour clinic for challenging behaviours, Kelly et al. (2008) found that over $80 \%$ of participants were reported by an informant to display inappropriate social behaviour on the Overt Behaviour Scale (OBS), making it the most frequently reported challenging behaviour, along with verbal aggression. In a sample of 507 patients with severe TBI who had not been specifically referred for behavioural problems, 33\% were reported to have displayed socially inappropriate behaviour on the $O B S$, making it the most commonly reported challenging behaviour (Sabaz et al., 2014). A summary of these studies and the rates of disinhibited behaviour they report is displayed in Table 2. Clearly, these estimates of prevalence vary greatly across studies. One way to explain this variation might be differences in the severity of injuries in the sample. Although these studies do not address this relationship explicitly, it is clear from an examination of Table 2 that this variable does not fully explain the variation. For instance, studies including participants who had an average post-traumatic amnesia (PTA) of 98 and 46 days respectively (Cantagallo \& Dimarco, 2002; Ponsford et al., 1995) reported half the rate of disinhibition than a sample who had an average PTA of 13 days (Johnson \& Balleny, 1996). It is more likely that the variation in prevalence rates can be explained by differences in outcome measures used, further highlighting the need for the field to reach a consensus on 
the definition and measurement of this construct. Overall, though, a review of the literature suggests that approximately $1 / 3$ of people with severe TBI have acquired social disinhibition. Table 2 about here.

\section{Associated outcomes}

Most research has focused on identifying psychosocial outcomes associated with neurobehavioural problems broadly, rather than those associated with social disinhibition more specifically. Caregiver burden/distress is the most commonly examined outcome in such studies, and is usually self-reported by the caregiver on a single item scale. For instance, Brooks and colleagues $(1893,1986)$ measure caregiver burden on a 7-point rating scale ranging from "I feel no strain as a result of changes in my spouse/relative" to "I feel severe strain...". This variable is also commonly measured using the Brief Symptom Inventory (BSI), on which caregivers rate the extent to which a list of patient symptoms have bothered them in the last week, with higher total scores showing higher distress. Brooks and McKinlay (1983) found that caregiver burden was related to personality change in the first year post injury, which included changes in the control of temper, social withdrawal, affection, lack of energy, cruelty, unreasonableness, immaturity and insensitivity. At 5 years post injury, caregiver burden was still strongly related to magnitude of personality change (Brooks, Campsie, Symington, Beattie, \& McKinlay, 1986). Neurobehavioural changes have consistently been shown to be better predictors of caregiver distress and burden than factors such as injury severity and physical, cognitive and emotional impairment (eg. Ergh, Rapport, Coleman, \& Hanks, 2002; Koskinen, 1998). Neurobehavioral function on the Neurobehavioural Rating Scale (NRS) has also been found to be related to family functioning reported by caregivers on the Family Environment Scale (FES) (Douglas \& Spellacy, 1996). Only two studies have focused more specifically on the relationship between disinhibition and caregiver burden. One study found that loss of emotional control, but not loss of motivation, on the $C B S$ was 
associated with mother's level of distress on the Leeds Scale of Depression and Anxiety (Kinsella, Packer, \& Olver, 1991). The other study found that inappropriateness on the Neuropsychology Behaviour and Affect Profile (NBAP) were more predictive of family functioning on the Family Assessment Device-General Functioning (FAD-GF) subscale and, to a lesser extent, caregiver stress on the Perceived Stress Scale (PSS), than other NBAP scales (Groom, Shaw, O'Connor, Howard, \& Pickens, 1998).

Neurobehavioural symptoms have also been found to be a better predictor of patient quality of life than physical or cognitive factors (Koskinen, 1998), where quality of life was measured on an author-developed scale which assessed life satisfaction across 6 domains (self-care, leisure, friendships, family, marriage and sexuality). Loss of emotional control on the $C B S$ has been found to predict whether a person with TBI falls into a low community integration or high community integration group, based on scores on the Community Integration Questionnaire (CIQ), the Community Integration Measure (CIM) and the Sydney Psychosocial Reintegration Scale (SPRS) (Winkler, Unsworth, \& Sloan, 2006). Another study found disinhibition, assessed by the FrSBe, was related to suicidal endorsement in the patient at both six and 12 months post injury (Juengst, Kumar, Arenth, \& Wagner, 2014). Further, inappropriate sexual behaviours, a manifestation of a disinhibition syndrome, can have important implications for social reintegration and can lead to legal problems among TBI patients (Simpson, Blaszczynski, \& Hodgkinson, 1999). The studies reporting outcomes associated with disinhibited behaviour after TBI are summarised in Table 4. Together these findings suggest that social disinhibition has a profound effect on both the person with TBI and their caregivers and family.

Table 4 about here.

\section{Neuropathological correlates of social disinhibition}


Damage to the orbitofrontal cortex and its connections with other brain regions

following TBI have been commonly associated with acquired disinhibition. Linscott, Knight, and Godfrey (1996) described a patient who sustained a right orbital contusion as a result of a severe TBI who was rated as being insensitive, egocentric and inappropriate in his use of affective expression and humour. Starkstein and Robinson (1997) reviewed the literature and concluded that lesions of the orbitofrontal cortex, caused by brain injury, tumours or strokes, were reliably associated with a disinhibition syndrome. Further, damage to frontal white matter tracts, which convey information between the orbitofrontal region and other brain areas, has been associated with response inhibition on a Stop Signal task and with parentrated inhibition in everyday life on the Inhibit scale of the Behaviour Rating Inventory of Executive Functioning (BRIEF) in children with TBI (Lipszyc et al., 2014). The orbitofrontal region is particularly vulnerable to injury during TBI because of its proximity to the bony protrusions and cavities of the inferior surface of the skull (Levin \& Kraus, 1994). In particular, acceleration/deceleration forces during motor vehicle accidents, the most common cause of severe TBI (Tate, McDonald, \& Lulham, 1998), can cause the brain to impact upon these bony surfaces, causing multifocal lesions in in the orbitofrontal region as well as shearing of axonal connections with other systems (Levin \& Kraus, 1994). Furthermore, diffuse axonal injury is particularly common in the frontal lobes following TBI (Bigler, 2007). Thus, moderate to severe TBI often results in damage to the orbitofrontal region either social disinhibition.

Further evidence for this claim comes from case reports of patients with lesions of the orbitofrontal cortex resulting from other neurological conditions or neurosurgery who have similarly been described as disinhibited (Barrash, Tranel, \& Anderson, 2000; Blair, 2004; 
Harlow, 1868; Malloy, Bihrle, Duffy, \& Cimino, 1993; Namiki et al., 2008; Rylander \& Frey, 1939). Further, studies of groups of orbitofrontal patients confirm this link. For instance, Logue, Durward, Pratt, Piercy, and Nixon (1968) found that $75 \%$ of their sample of 79 survivors of rupture of anterior communicating artery aneurysms with orbitofrontal injury exhibited personality changes, including being more outspoken, irritable and tactless.

Disinhibited behaviour has also been described in patients with orbitofrontal tumours (Hunter, Blackwoo, \& Bull, 1968) and inferior frontal lobe infarction (Bogousslavsky \& Regli, 1990). Patients with orbitofrontal lesions have been found to be socially inappropriate compared to healthy controls, including being argumentative, critical, impatient, inappropriately intimate, tasteless and vulgar (Barrash et al., 2000; Beer, John, Scabini, \& Knight, 2006; Bramham, Morris, Hornak, Bullock, \& Polkey, 2009; Cicerone \& Tanenbaum, 1997; Rolls, Hornak, Wade, \& McGrath, 1994; Stuss \& Benson, 1984). Further, orbitofrontal neurodegeneration in behavioural-variant frontotemporal dementia (bvFTD) has been consistently linked with disinhibition on the NPI (Hornberger, Geng, et al., 2011; Peters et al., 2006). Thus, there exists strong evidence from a range of neurological patient groups that acquired social disinhibition results from damage to the orbitofrontal cortex and its connections with other brain regions.

The problem for TBI, of course, is that while the orbitofrontal regions are implicated, there are many other regions and systems, including white matter tracts that are often compromised in such injuries. Without accurate and precise measurement, it is difficult to ascertain whether the phenotype of social disinhibition is the same in people with TBI versus more circumscribed lesions. Even more difficult to ascertain is whether the underlying mechanisms are identical. Certainly a number of potential mechanisms have been proposed.

\section{Proposed Mechanisms}


Although it is clear that the orbitofrontal region is critically involved in adaptive interpersonal behaviour, there has been less agreement regarding the underlying cognitive mechanism. One candidate mechanism for disinhibited behaviour is inhibitory control or response inhibition (Tate, 1999). Response inhibition, the ability to inhibit a pre-potent response, as indexed by such tasks as the go/no-go task, the SART, CPT and stop-signal test has been shown to be impaired after TBI yielding a moderate effect size $(d=0.5)$ across numerous studies (Dimoska-Di Marco et al., 2011). As mentioned previously, though, evidence as to whether these impairments are actually related to socially disinhibited behaviour has been inconclusive. These inconsistencies suggest that impaired inhibitory control cannot fully explain social disinhibition after TBI.

Blair and Cipolotti (2000) have proposed that the orbitofrontal cortex is involved in Social Response Reversal (SRR), a system which uses social cues, especially those portraying anger or disapproval, to guide social behaviour. Angry expressions are known to curtail the behaviour of others in situations where social rules or expectations have been violated (Averill, 2012). The Social Response Reversal system may break down if there is an inability to recognise negative emotional expressions which are triggered in response to inappropriate behaviour. Alternatively, it may break down if there is an inability to change ongoing behaviour based on such feedback. Both of these mechanisms have been considered in the literature.

Emotion perception impairments have widely been considered to play a role in social disturbances following TBI. Since facial and vocal expressions of emotion can act as social rewards or punishments (Heberlein, Padon, Gillihan, Farah, \& Fellows, 2008), impairment in the ability to recognise these emotions has clear implications for social behaviour and learning. For instance, if a speaker with brain injury is unable to recognise anger, disgust or discomfort in the person they are interacting with, they are unable to experience the social 
punishment that might otherwise curb their behaviour. Thus, the inappropriate behaviours which characterise social disinhibition, such as making insensitive comments, being tasteless or vulgar, interrupting others and inappropriate self-disclosure remain unchecked.

Impairments in recognition of emotion following TBI have been widely demonstrated (for a review see Bornhofen \& McDonald, 2008). Beyond this theoretical causal relationship, disinhibited behaviour and emotion perception impairments may share the same underlying neuropathology since orbitofrontal damage has also been repeatedly linked with both facial and vocal emotion perception deficits (eg. Barrash et al., 2000; Blair, Morris, Frith, Perrett, \& Dolan, 1999; Heberlein et al., 2008) and with disinhibition. However, evidence for an association between emotion perception impairments and social disturbances after TBI has been mixed. Watts and Douglas (2006) found a correlation between impairment in the interpretation of facial emotion after TBI on The Awareness of Social Inference Test (TASIT) and informant-rated communication competence on the La Trobe Communication Questionnaire (LCQ) in a sample of 12 people with severe TBI. Another study found relationships between two facial emotion recognition tasks and social integration on the Revised Craig Handicap Assessment and Reporting Technique (R-CHART) in a sample of 13 people with severe TBI (Knox \& Douglas, 2009). Further, McDonald et al. (2004) found that emotion recognition on the TASIT was related to the ability to use humour appropriately in a social context, as rated from a videotaped interaction. These findings suggest that impaired recognition of facial emotion after TBI reduces the capacity to respond appropriately in social interactions. However, the studies outlined above which have demonstrated a relationship between emotion perception and social outcome have largely relied on small sample sizes. Other studies have failed to find this relationship. Milders and colleagues (Milders et al., 2003; Milders, Ietswaart, Crawford, \& Currie, 2008), for example, failed to find any significant relationships between recognition of facial or vocal emotion after TBI and a 
number of different questionnaires designed to assess emotional and behavioural functioning of neurological patients, including the NBAP, the DEX, the Social Integration Questionnaire (SIQ), and the Katz Adjustment Scale-Revised (KAS-R). Further, Beer, Heerey, Keltner, Scabini, and Knight (2003) found inappropriate social behaviour in participants with longstanding bilateral orbitofrontal damage due to TBI, despite evidence of intact recognition of basic facial expressions.

One reason for this inconsistency may be the nature of the emotion perceptions tasks used. Research in this area has tended to use forced-choice recognition tasks, in which participants must choose the correct label for the presented emotion from a list of alternatives. However, providing a verbal label for an expressed emotion is not a standard requirement in social situations. Thus, these sorts of tests may not be an ecologically valid way of measuring the emotion perception deficits which impact upon social behaviour. Another source of inconsistency might arise from the wide range of outcome measures used to measure the construct of social competence. Further, studies have tended to focus on the relationship between emotion perception and social outcome broadly, rather than looking at the relationship between emotion perception and disinhibited behaviour specifically. In response to these issues, the current authors recently conducted the first study to assess the relationship between emotion perception and social disinhibition specifically after TBI and found no evidence for an association (Author citation). Thus, the evidence to date suggests that impaired emotion perception may play a role in social competence broadly after TBI, yet there has been no evidence to suggest that it plays a role in disinhibited behaviour specifically.

If not related to a problem with interpreting negative social feedback in the form of emotional expressions, disinhibited behaviour may be the result of an inability to actually update behaviour when these signals of disapproval are received. It is well established that 
animals and humans with orbitofrontal damage, but not those with dorsolateral prefrontal damage, are unable to update their responding to reflect this change in reward contingencies (eg. Fellows \& Farah, 2003). Further, neuroimaging studies have demonstrated that reversal learning tasks activate the orbitofrontal cortex in normal subjects (O'doherty, Kringelbach, Rolls, Hornak, \& Andrews, 2001). Thus, reversal learning is a hallmark of orbitofrontal function, which has prompted suggestions that inappropriate social behaviour exhibited by patients with orbitofrontal damage may be related to dysfunction in altering behaviour appropriately in response to a change in reinforcement contingencies. The orbitofrontal cortex may be critical for normal social behaviour because it updates stimulus-reinforcement contingencies when they become inappropriate, for instance, when something about the social context changes. In support of this theory, Rolls et al. (1994) found that patients with orbitofrontal damage performed poorly on a reversal learning task compared with patients with damage to other brain regions. Further their performance on this task correlated negatively with their level of disinhibited/socially inappropriate behaviour. More recently, Osborne-Crowley, Mcdonald, and Rushby (2016) found that individuals with TBI who exhibited disinhibited behaviours were impaired at updating responding based on changes in social reinforcement contingencies compared to those who were not disinhibited. Thus, the limited evidence to date suggests reversal learning impairments caused by damage to the orbitofrontal cortex may play a role in disinhibited behaviour after TBI.

While reversal learning and emotion perception have received the most attention in the literature as potential mechanisms of social disinhibition, other theories have also been proposed. Grafman interpreted patient's disinhibition in terms of an inability to access 'social schema knowledge' stored in the frontal lobes, which provides a template for socially acceptable behaviour (Grafman et al., 1996). However, this theory is contradicted by the observation that patients with social disinhibition often have preserved general knowledge of 
what behaviours would be appropriate (Kocka \& Gagnon, 2014). For instance, Saver and Damasio (1991) observed that disinhibited patient EVR showed intact social knowledge on tasks such as the cartoon predictions test and the moral judgement interview. Another study showed that participants with TBI did not perform differently to control participants on the Implicit Association Test, suggesting that they have normal access to social stereotypes (McDonald, Saad, \& James, 2011). The social impairments of people with TBI have also been interpreted as a result of deficits in theory of mind (Muller et al., 2010). Loss of theory of mind ability results in impaired judgement as to what another person might be thinking. This, like poor emotion perception, could be seen as an impediment to the ability to tailor interpersonal behaviour appropriately. Theory of mind has been shown to be impaired after TBI on a range of tasks of varying difficulty (eg. Muller et al., 2010). However, there is little evidence to suggest an association between these theory of mind deficits and social disinhibition. Milders et al. (2003), for instance, found no association between detecting social faux pas and relatives' ratings of behavioural problems after TBI. Further, since social situation are often more cognitively demanding than non-social situations, difficulties with executive function, attention and memory may play a role, although it has not yet been investigated.

Finally, lack of self-awareness may be a maintaining factor of disinhibited behaviour after TBI. Deficits in self-awareness have been consistently reported following severe TBI (FitzGerald, Carton, O'Keeffe, Coen, \& Dockree, 2012), particularly for social competencies (Allen \& Ruff, 1990). A relationship between lack of self-awareness and behavioural disturbance following TBI has been found in at least one study (Bach \& David, 2006). Further, in a study looking at disinhibited self-disclosure after orbitofrontal lesions, patients were found to be unaware of their own behaviour being inappropriate (Beer et al., 2003). 
Such an inability to monitor one's own behaviour and to be aware of its inappropriateness may be an important barrier to overcoming these social difficulties.

In sum, several cognitive mechanisms for social disinhibition have been proposed, including poor inhibitory control, impaired social cognition (emotion perception and theory of mind), poor reversal learning, loss of social knowledge and poor self-awareness. Of these, the suggestion that reversal learning impairment plays a role in social disinhibition after TBI is the most supported by the evidence to date. However, in general, investigation of these mechanisms has been thwarted by a lack of consensus surrounding the definition of social disinhibition and inconsistent measurement of the construct.

\section{Treatment}

To the authors' knowledge, there is currently no published data on effectiveness of any treatment programs for reducing disinhibited behaviours after TBI specifically. This is in contrast to the array of anger management programmes which have been developed for people with a TBI. The continued focus on anger problems in the literature rather than disinhibition is curious, given that social disinhibition has been reported at similar rates (Kelly et al., 2008). While anger may be related to disinhibition, it represents a narrow category of emotional response in relation to the wide repertoire of social behaviours that can be disrupted by disinhibition. Social skills training for people with TBI has a broader behavioural focus and has also been the subject of much research. Social skills training is usually predicated upon the assumption that participants do not have certain skills or knowledge and that these can be learned. On the other hand, disinhibited behaviour after TBI does not appear to be the result of a lack of social knowledge but rather to do with problems in inhibiting inappropriate responses or recognising when behaviour is inappropriate (Ylvisaker, Turkstra, \& Coelho, 2005). Consequently, social skills training may not target disinhibition effectively. Behavioural interventions are another common approach to treating 
socially disinhibited behaviour, emphasising the management of behaviour by deliberately manipulating the antecedents and consequences of problem behaviours in order to reduce the frequency with which they occur (and conversely to increase the frequency of replacement positive social behaviours). There is ample empirical support for the effectiveness of behavioural strategies for behavioural problems more broadly, but no research has focused on their usefulness specifically for those with disinhibition after TBI (Arciniegas \& Wortzel, 2014). Further, these approaches aim to reduce the frequency of problem behaviours, but do not focus on rehabilitating underlying impairments. Overall, it is clear that social disinhibition is a remediation target in its own right, and one that has been neglected to date. McAllister (2008) has noted that a clear understanding of what is causing the disinhibited behaviour is important in the development of effective rehabilitation strategies. More research is necessary before a conclusive understanding of the mechanisms underlying social disinhibition is attained. However, the findings reviewed above do suggest some potential avenues for treatment which should be explored. Most notably, the association between reversal learning deficits and social disinhibition suggests that remediation of reversal learning deficits may help reduce socially disinhibited behaviour.

Further, since impairments in self-awareness of ongoing behaviour may contributing to the maintenance of socially disinhibited behaviour, rehabilitation targeting self-awareness might improve this behaviour. Patients with orbitofrontal lesions who lack embarrassment and are unaware of the inappropriateness of their behaviour can be encouraged to feel embarrassment by the use of videoed feedback of their disinhibited behaviour (Beer et al., 2003). This suggests that helping people monitor their own behaviour in order to make online behavioural adjustments may be a fruitful avenue for treatment. In line with this, the effectiveness of 20 hours of interpersonal process recall (IPR), which includes a structured review of conversation with feedback from the conversation partner, was demonstrated in 
533

534

535

536

537

538

539

540

541

542

543

544

545

546

547

548

549

550

551

552

553

554

555

556

557

participants with social integration problems after TBI (Helffenstein \& Wechsler, 1982).

Compared to a control group who received 20 1-hour sessions of non-therapeutic attention, the IPR group improved at a post-treatment assessment and at a one-month follow-up assessment on interpersonal and communication skills assessed by professional staff members blind to group allocation. However, it is unclear what specific behavioural problems these patients suffered. So while self-awareness training may have some potential for rehabilitating social disinhibition in TBI, research is needed to determine whether this can reduce the frequency of disinhibited behaviours and improve interpersonal relationships. Importantly, deficits in self-awareness may also be a hindrance to the rehabilitation itself (FitzGerald et al., 2012). For instance, research has shown that greater self-awareness after TBI is associated with rehabilitation adherence and greater motivation to change behaviour (Fleming, Strong, \& Ashton, 1998; Trahan, Pepin, \& Hopps, 2006). When developing any rehabilitation programme for a disinhibited individual, then, it is important to consider these barriers.

\section{Conclusions}

Social disinhibition is among the most common of behavioural changes reported after TBI, and appears to be present in about one third of patients with severe TBI. Evidence from a range of neurologic patients suggests that social disinhibition results from damage to the orbitofrontal region of the brain and its connections with other brain regions. These disinhibited behaviours have been shown to be related to higher caregiver distress, poorer family functioning and community reintegration, legal problems and even suicidal endorsement. A number of potential mechanisms underlying socially disinhibited behaviour have often been speculated about in the literature. While there still exists little research investigating these mechanism, the most evidence to date supports a role of reversal learning impairment in socially disinhibited behaviour. Of course, considering the multifarious nature 
558 of brain damage after TBI, it is possible that there are a number of mechanisms at play. An 559 improved understanding of what causes disinhibited behaviour after TBI is the critical next 560 step for research as it will be necessary for the development of effective treatment strategies 561 aimed at the rehabilitation of underlying impairments. 
References

564

565

566

567

568

569

570

571

572

573

574

575

576

577

578

579

580

581

582

583

584

585

586

587

Allen, C. C., \& Ruff, R. M. (1990). Self-rating versus neuropsychological performance of moderate versus severe head-injured patients. Brain Injury, 4(1), 7-17. doi: $10.3109 / 02699059009026143$

Arciniegas, D. B., \& Wortzel, H. S. (2014). Emotional and behavioral dyscontrol after traumatic brain injury. Psychiatric Clinics of North America, 37(1), 31-53. doi: 10.1016/j.psc.2013.12.001

Averill, J. R. (2012). Anger and aggression: An essay on emotion: Springer Science \& Business Media.

Bach, L. J., \& David, A. S. (2006). Self-awareness after acquired and traumatic brain injury. Neuropsychological Rehabilitation, 16(4), 397-414. doi: $10.1080 / 09602010500412830$

Barrash, J., Anderson, S. W., Jones, R. D., \& Tranel, D. (1997). The Iowa rating scales of personality change: reliability and validity. Journal of the International Neuropsychological Society, 3(1), 27-28.

Barrash, J., Tranel, D., \& Anderson, S. W. (2000). Acquired personality disturbances associated with bilateral damage to the ventromedial prefrontal region. Developmental Neuropsychology, 18(3), 355-381. doi: 10.1207/S1532694205Barrash

Beer, J. S., Heerey, E. A., Keltner, D., Scabini, D., \& Knight, R. T. (2003). The regulatory function of self-conscious emotion: insights from patients with orbitofrontal damage. Journal of Personality and Social Psychology, 85(4), 594-604. doi: 10.1037/00223514.85 .4 .594

Beer, J. S., John, O. P., Scabini, D., \& Knight, R. T. (2006). Orbitofrontal cortex and social behavior: integrating self-monitoring and emotion-cognition interactions. Journal of Cognitive Neuroscience, 18(6), 871-879. doi: 10.1162/jocn.2006.18.6.871 
Bennett, P. C., Ong, B., \& Ponsford, J. (2005). Measuring executive dysfunction in an acute rehabilitation setting: Using the dysexecutive questionnaire (DEX). Journal of the International Neuropsychological Society, 11(04), 376-385.

Bigler, E. D. (2007). Anterior and middle cranial fossa in traumatic brain injury: Relevant neuroanatomy and neuropathology in the study of neuropsychological outcome. Neuropsychology, 21(5), 515-531. doi: 10.1037/0894-4105.21.5.515 17784800

Bigler, E. D., \& Maxwell, W. L. (2013). Overview of Traumatic Brain Injury. In D. B. Arciniegas, N. D. Zasler, R. D. Vanderploeg \& M. S. Jaffee (Eds.), Management of Adults with Traumatic Brain Injury: American Psychiatric Publishing.

Blair, R. J. R. (2004). The roles of orbital frontal cortex in the modulation of antisocial behavior. Brain and Cognition, 55(1), 198-208. doi: 10.1016/S0278-2626(03)00276-8

Blair, R. J. R., \& Cipolotti, L. (2000). Impaired social response reversal 'A case of acquired sociopathy'. Brain, 123(6), 1122-1141. doi: 10.1093/brain/123.6.1122

Blair, R. J. R., Morris, J. S., Frith, C. D., Perrett, D. I., \& Dolan, R. J. (1999). Dissociable neural responses to facial expressions of sadness and anger. Brain, 122(5), 883-893. doi: $10.1093 /$ brain/122.5.883

Bogousslavsky, J., \& Regli, F. (1990). Anterior Cerebral-Artery Territory Infarction in the Lausanne Stroke Registry - Clinical and Etiologic Patterns. Archives of Neurology, 47(2), 144-150. doi: 10.1001/archneur.1990.00530020040012

Bond, F., \& Godfrey, H. P. (1997). Conversation with traumatically brain injured individuals: A controlled study of behavioural changes and their impact. Brain Injury, 11(5), 319330. doi: $10.1080 / 026990597123476$

Bornhofen, C., \& McDonald, S. (2008). Emotion perception deficits following traumatic brain injury: A review of the evidence and rationale for intervention. Journal of the 
International Neuropsychological Society, 14(4), 511-525. doi: $10.1017 / \mathrm{S} 1355617708080703$

Bramham, J., Morris, R., Hornak, J., Bullock, P., \& Polkey, C. (2009). Social and emotional functioning following bilateral and unilateral neurosurgical prefrontal cortex lesions. Journal of Neuropsychology, 3(1), 125-143. doi: 10.1348/174866408X293994

Braun, C. M. J., Daigneault, S., \& Champagne, D. (1989). Information-Processing Deficits as Indexed by Reaction-Time Parameters in Severe Closed Head-Injury. International Journal of Clinical Neuropsychology, 11(4), 167-176. doi: 10.1093/arclin/4.2.103

Brooks, N., Campsie, L., Symington, C., Beattie, A., \& McKinlay, W. (1986). The five year outcome of severe blunt head injury: a relative's view. Journal of Neurology, Neurosurgery \& Psychiatry, 49(7), 764-770. doi: 10.1136/jnnp.49.7.764

Brooks, N., \& McKinlay, W. (1983). Personality and behavioural change after severe blunt head injury - a relative's view. Journal of Neurology, Neurosurgery \& Psychiatry, 46(4), 336-344. doi: 10.1136/jnnp.46.4.336

Burgess, P. W., Alderman, N., Evans, J., Emslie, H., \& Wilson, B. A. (1998). The ecological validity of tests of executive function. Journal of the International Neuropsychological Society, 4(6), 547-558.

Cantagallo, A., \& Dimarco, F. (2002). Prevalence of neuropsychiatric disorders in traumatic brain injury patients. Europa Medicophysica, 38(4), 167-178.

Cicerone, K. D. (1997). Clinical sensitivity of four measures of attention to mild traumatic brain injury. Clinical Neuropsychologist, 11(3), 266-272. doi: $10.1080 / 13854049708400455$

Cicerone, K. D., \& Tanenbaum, L. N. (1997). Disturbance of social cognition after traumatic orbitofrontal brain injury. Archives of Clinical Neuropsychology, 12(2), 173-188. doi: 10.1093/arclin/12.2.173 
637

638

639

640

641

642

643

644

645

646

647

648

649

650

651

652

653

654

655

656

657

658

659

660

Ciurli, P., Formisano, R., Bivona, U., Cantagallo, A., \& Angelelli, P. (2011).

Neuropsychiatric disorders in persons with severe traumatic brain injury: prevalence, phenomenology, and relationship with demographic, clinical, and functional features. The Journal of Head Trauma Rehabilitation, 26(2), 116-126. doi: 10.1097/HTR.0b013e3181dedd0e

Cummings, J. L. (1997). The Neuropsychiatric Inventory Assessing psychopathology in dementia patients. Neurology, 48(5 Suppl 6), 10S-16S. doi: 10.1212/WNL.48. 5_Suppl_6.10S

Cummings, J. L., Mega, M., Gray, K., Rosenbergthompson, S., Carusi, D. A., \& Gornbein, J. (1994). The Neuropsychiatric Inventory - Comprehensive Assessment of Psychopathology in Dementia. Neurology, 44(12), 2308-2314. doi: 10.1212/WNL.44.12.2308

Dimoska-Di Marco, A., McDonald, S., Kelly, M., Tate, R. L., \& Johnstone, S. (2011). A meta-analysis of response inhibition and Stroop interference control deficits in adults with traumatic brain injury (TBI). Journal of Clinical and Experimental Neuropsychology, 33(4), 471-485. doi: 10.1080/13803395.2010.53315821229434

Douglas, J. M., \& Spellacy, F. J. (1996). Indicators of long-term family functioning following severe traumatic brain injury in adults. Brain Injury, 10(11), 819-840. doi: $10.1080 / 0269905961239368905160$

Draper, K., \& Ponsford, J. (2008). Cognitive functioning ten years following traumatic brain injury and rehabilitation. Neuropsychology, 22(5), 618-625. doi: 10.1037/08944105.22.5.618 18763881

Elsass, L., \& Kinsella, G. (1987). Social interaction following severe closed head injury. Psychological Medicine, 17(1), 67-78. doi: 10.1017/S003329170001299X 3575579 
Ergh, T. C., Rapport, L. J., Coleman, R. D., \& Hanks, R. A. (2002). Predictors of caregiver and family functioning following traumatic brain injury: Social support moderates caregiver distress. The Journal of Head Trauma Rehabilitation, 17(2), 155-174. doi: 10.1097/00001199-200204000-00006 11909512

Farrell, A. D., Rabinowitz, J. A., Wallander, J. L., \& Curran, J. P. (1985). An evaluation of two formats for the intermediate-level assessment of social skills. Behavioral Assessment, 7(2), 155-171.

Fellows, L. K., \& Farah, M. J. (2003). Ventromedial frontal cortex mediates affective shifting in humans: evidence from a reversal learning paradigm. Brain, 126(8), 1830-1837. doi: $10.1093 /$ brain/awg180

FitzGerald, M. C. C., Carton, S., O'Keeffe, F., Coen, R. F., \& Dockree, P. M. (2012). Impaired self-awareness following acquired brain injury: Current theory, models and anatomical understanding. The Irish Journal of Psychology, 33(2-3), 78-85. doi: $10.1080 / 03033910.2012 .708898$

Fleming, J. M., Strong, J., \& Ashton, R. (1998). Cluster analysis of self-awareness levels in adults with traumatic brain injury and relationship to outcome. The Journal of Head Trauma Rehabilitation, 13(5), 39-51. doi: 10.1097/00001199-199810000-00006 9753534

Grace, J., \& Malloy, P. F. (2001). Frontal Systems Behavior Scale Professional Manual. Lutz, FL: Psychological Assessment Resources: Inc.

Grace, J., Stout, J., \& Malloy, P. (1999). Assessing frontal lobe behavioral syndromes with the frontal lobe personality scale. Assessment, 6(3), 269-284. doi: $10.1177 / 107319119900600307$ 
Grafman, J., Schwab, K., Warden, D., Pridgen, A., Brown, H. R., \& Salazar, A. M. (1996). Frontal lobe injuries, violence, and aggression: A report of the Vietnam Head Injury Study. Neurology, 46(5), 1231-1238. doi: 10.1212/WNL.46.5.1231

Groom, K. N., Shaw, T. G., O'Connor, M. E., Howard, N. I., \& Pickens, A. (1998). Neurobehavioral symptoms and family functioning in traumatically brain-injured adults. Archives of Clinical Neuropsychology, 13(8), 695-711. doi: 10.1016/S0887$6177 \% 2898 \% 2900005-514590629$

Hanna-Pladdy, B. (2007). Dysexecutive syndromes in neurologic disease. Journal of Neurologic Physical Therapy, 31(3), 119-127. doi: 10.1097/NPT.0b013e31814a63c2

Harlow, J. M. (1868). Recovery from the passage of an iron bar through the head. Publications of the Massachusetts Medical Society, 2(3), 327-246. doi: $10.1177 / 0957154 \times 9300401407$

Hathaway, S. R., \& McKinley, J. R. (1967). The Minnesota Multiphasic Personality Inventory Manual. New York: Psychological Corporation.

Heberlein, A. S., Padon, A. A., Gillihan, S. J., Farah, M. J., \& Fellows, L. K. (2008). Ventromedial Frontal Lobe Plays a Critical Role in Facial Emotion Recognition. Journal of Cognitive Neuroscience, 20(4), 721-733. doi: 10.1162/jocn.2008.20049

Helffenstein, D. A., \& Wechsler, F. S. (1982). The Use of Interpersonal Process Recall (Ipr) in the Remediation of Interpersonal and Communication Skill Deficits in the Newly Brain-Injured. Clinical Neuropsychology, 4(3), 139-143.

Hornberger, M., Geng, J., \& Hodges, J. R. (2011). Convergent grey and white matter evidence of orbitofrontal cortex changes related to disinhibition in behavioural variant frontotemporal dementia. Brain, 134(9), 2502-2512. doi: 10.1093/brain/awr173

Hornberger, M., Savage, S., Hsieh, S., Mioshi, E., Piguet, O., \& Hodges, J. R. (2011). Orbitofrontal dysfunction discriminates behavioral variant frontotemporal dementia 

from Alzheimer's disease. Dementia and Geriatric Cognitive Disorders, 30(6), 547552. doi: $10.1159 / 000321670$

Hunter, R., Blackwoo, W., \& Bull, J. (1968). 3 Cases of Frontal Meningiomas Presenting Psychiatrically. British Medical Journal, 3(5609), 9-10.

Hyder, A. A., Wunderlich, C. A., Puvanachandra, P., Gururaj, G., \& Kobusingye, O. C. (2007). The impact of traumatic brain injuries: A global perspective. Neurorehabilitation, 22(5), 341-353.

Johnson, R., \& Balleny, H. (1996). Behaviour problems after brain injury: Incidence and need for treatment. Clinical Rehabilitation, 10(2), 173-180. doi: $10.1177 / 026921559601000215$

Juengst, S. B., Kumar, R. G., Arenth, P. M., \& Wagner, A. K. (2014). Exploratory associations with tumor necrosis factor-alpha, disinhibition and suicidal endorsement after traumatic brain injury. Brain, Behavior, and Immunity, 41, 134-143. doi: 10.1016/j.bbi.2014.05.02024928066

Kelly, G., Brown, S., Todd, J., \& Kremer, P. (2008). Challenging behaviour profiles of people with acquired brain injury living in community settings. Brain Injury, 22(6), 457-470. doi: 10.1080/02699050802060647 18465387

Kelly, G., Todd, J., Simpson, G., Kremer, P., \& Martin, C. (2006). The overt behaviour scale (OBS): A tool for measuring challenging behaviours following $\mathrm{ABI}$ in community settings. Brain Injury, 20(3), 307-319. doi: 10.1080/02699050500488074

Kinsella, G., Packer, S., \& Olver, J. H. (1991). Maternal reporting of behaviour following very severe blunt head injury. Journal of Neurology, Neurosurgery \& Psychiatry, 54(5), 422-426. doi: 10.1136/jnnp.54.5.422 
Knox, L., \& Douglas, J. (2009). Long-term ability to interpret facial expression after traumatic brain injury and its relation to social integration. Brain and Cognition, 69(2), 442-449. doi: 10.1016/j.bandc.2008.09.009 18951674

Kocka, A., \& Gagnon, J. (2014). Definition of Impulsivity and Related Terms Following Traumatic Brain Injury: A Review of the Different Concepts and Measures Used to Assess Impulsivity, Disinhibition and other Related Concepts. Behavioral Sciences, 4(4), 352-370. doi: 10.3390/bs4040352

Koskinen, S. (1998). Quality of life 10 years after a very severe traumatic brain injury (TBI): the perspective of the injured and the closest relative. Brain Injury, 12(8), 631-648. doi: $10.1080 / 026990598122205$

Laidlaw, T. M. (1993). Hypnosis and attention deficits after closed head injury. International Journal of Clinical and Experimental Hypnosis, 41(2), 97-111. doi: $10.1080 / 002071493084145418468107$

Langlois, J. A., Rutland-Brown, W., \& Wald, M. M. (2006). The epidemiology and impact of traumatic brain injury - A brief overview. Journal of Head Trauma Rehabilitation, 21(5), 375-378. doi: 10.1097/00001199-200609000-00001

Levin, H. S., \& Kraus, M. F. (1994). The frontal lobes and traumatic brain injury. The Journal of Neuropsychiatry and Clinical Neurosciences, 6(4), 443-443. doi: 10.1176/jnp.6.4.443

Lezak, M. D., \& O'Brien, K. P. (1988). Longitudinal-Study of Emotional, Social, and Physical Changes after Traumatic Brain Injury. Journal of Learning Disabilities, 21(8), 456-463. doi: 10.1177/002221948802100802

Lin, M. R., Chiu, W. T., Chen, Y. J., Yu, W. Y., Huang, S. J., \& Tsai, M. D. (2010). Longitudinal Changes in the Health-Related Quality of Life During the First Year 
After Traumatic Brain Injury. Archives of Physical Medicine and Rehabilitation, 91(3), 474-480. doi: 10.1016/j.apmr.2009.10.031

Linscott, R. J., Knight, R. G., \& Godfrey, H. P. D. (1996). The Profile of Functional Impairment in Communication (PFIC): A measure of communication impairment for clinical use. Brain Injury, 10(6), 397-412. doi: 10.1080/026990596124269

Lipszyc, J., Levin, H., Hanten, G., Hunter, J., Dennis, M., \& Schachar, R. (2014). Frontal white matter damage impairs response inhibition in children following traumatic brain injury. Archives of Clinical Neuropsychology, 29(3), 289-299. doi: 10.1093/arclin/acu004

Logue, V., Durward, M., Pratt, R. T. C., Piercy, M., \& Nixon, W. L. B. (1968). Quality of Survival after Rupture of an Anterior Cerebral Aneurysm. British Journal of Psychiatry, 114(507), 137-140. doi: 10.1192/bjp.114.507.137

Malloy, P., Bihrle, A., Duffy, J., \& Cimino, C. (1993). The orbitomedial frontal syndrome. Archives of Clinical Neuropsychology, 8(3), 185-201. doi: 10.1016/08876177(93)90035-Y

Marsh, N. V., \& Knight, R. G. (1991). Behavioral assessment of social competence following severe head injury. Journal of Clinical and Experimental Neuropsychology, 13(5), 729-740. doi: $10.1080 / 01688639108401086$

McAllister, T. W. (2008). Neurobehavioral sequelae of traumatic brain injury: evaluation and management. World Psychiatry, 7(1), 3-10. doi: 10.1002/j.2051-5545.2008.tb00139.x

McDonald, S., Flanagan, S., Martin, I., \& Saunders, C. (2004). The ecological validity of TASIT: A test of social perception. Neuropsychological Rehabilitation, 14(3), 285302. doi: $10.1080 / 09602010343000237$

McDonald, S., Saad, A., \& James, C. (2011). Social dysdecorum following severe traumatic brain injury: Loss of implicit social knowledge or loss of control? Journal of Clinical 
and Experimental Neuropsychology, 33(6), 619-630. doi:

$$
10.1080 / 13803395.2011 .553586
$$

McKinlay, W., Brooks, N., Bond, M., Martinage, D., \& Marshall, M. (1981). The short-term outcome of severe blunt head injury as reported by relatives of the injured persons. Journal of Neurology, Neurosurgery \& Psychiatry, 44(6), 527-533. doi: 10.1136/jnnp.44.6.527

Milders, M., Fuchs, S., \& Crawford, J. R. (2003). Neuropsychological impairments and changes in emotional and social behaviour following severe traumatic brain injury. Journal of Clinical and Experimental Neuropsychology, 25(2), 157-172. doi: 10.1076/jcen.25.2.157.13642

Milders, M., Ietswaart, M., Crawford, J. R., \& Currie, D. (2008). Social behavior following traumatic brain injury and its association with emotion recognition, understanding of intentions, and cognitive flexibility. Journal of the International Neuropsychological Society, 14(2), 318-326. doi: 10.1017/S1355617708080351

Monsalve, B. C., Guitart, M. B., Lopez, R., Vilasar, A. B., \& Quemada, J. I. (2012). Psychopatological evaluation of traumatic brain injury patients with the Neuropsychiatric Inventory. Revista De Psiquiatria Y Salud Mental, 5(3), 160-166. doi: 10.1016/j.rpsm.2012.02.004

Muller, F., Simion, A., Reviriego, E., Galera, C., Mazaux, J. M., Barat, M., \& Joseph, P. A. (2010). Exploring theory of mind after severe traumatic brain injury. Cortex, 46(9), 1088-1099. doi: 10.1016/j.cortex.2009.08.014

Namiki, C., Yamada, M., Yoshida, H., Hanakawa, T., Fukuyama, H., \& Murai, T. (2008). Small orbitofrontal traumatic lesions detected by high resolution MRI in a patient with major behavioural changes. Neurocase, 14(6), 474-479. doi: $10.1080 / 13554790802459494$ 
Narayan, R. K., Michel, M. E., Ansell, B., Beathmann, A., Biegon, A., Bracken, M. B., . . Choi, S. C. (2002). Clinical trials in head injury. Journal of Neurotrauma, 19(5), 503557. doi: $10.1089 / 089771502753754037$

Nelson, L. D., Drebing, C., Satz, P., \& Uchiyama, C. (1998). Personality change in head trauma: A validity study of the Neuropsychology Behavior and Affect Profile. Archives of Clinical Neuropsychology, 13(6), 549-560. doi: doi:10.1016/S08876177(97)00052-8

Nelson, L. D., Satz, P., Mitrushina, M., Van Gorp, W., Cicchetti, D., Lewis, R., \& Van Lancker, D. (1989). Development and validation of the Neuropsychology Behavior and Affect Profile. Psychological Assessment: A Journal of Consulting and Clinical Psychology, 1(4), 266-272. doi: 10.1037/1040-3590.1.4.266

O'Connell, R. G., Dockree, P. M., Bellgrove, M. A., Turin, A., Ward, S., Foxe, J. J., \& Robertson, I. H. (2009). Two types of action error: electrophysiological evidence for separable inhibitory and sustained attention neural mechanisms producing error on go/no-go tasks. Journal of Cognitive Neuroscience, 21(1), 93-104. doi: 10.1162/jocn.2009.21008

O'doherty, J., Kringelbach, M. L., Rolls, E., Hornak, J., \& Andrews, C. (2001). Abstract reward and punishment representations in the human orbitofrontal cortex. Nature Neuroscience, 4, 95-102. doi: 10.1038/82959

Oddy, M., Coughlan, T., Tyerman, A., \& Jenkins, D. (1985). Social adjustment after closed head injury: a further follow-up seven years after injury. Journal of Neurology, Neurosurgery \& Psychiatry, 48(6), 564-568. doi: 10.1136/jnnp.48.6.564

Osborne-Crowley, K., McDonald, S., \& Francis, H. (2015). Development of an observational measure of social disinhibition after traumatic brain injury. Journal of Clinical and 
Experimental Neuropsychology, Advanced online publication. doi: $10.1080 / 13803395.2015 .1115824$

Osborne-Crowley, K., Mcdonald, S., \& Rushby, J. A. (2016). Role of reversal learning impairment in social disinhibition following severe traumatic brain injury. Journal of the International Neuropsychological Society, 22(3), 303-313. doi: $10.1017 / \mathrm{S} 1355617715001277$

Peters, F., Perani, D., Herholz, K., Holthoff, V., Beuthien-Baumann, B., Sorbi, S., . . . Collette, F. (2006). Orbitofrontal dysfunction related to both apathy and disinhibition in frontotemporal dementia. Dementia and Geriatric Cognitive Disorders, 21(5), 373379. doi: $10.1159 / 000091898$

Ponsford, J. L., Olver, J. H., \& Curran, C. (1995). A Profile of Outcome - 2 Years after Traumatic Brain Injury. Brain Injury, 9(1), 1-10. doi: 10.3109/02699059509004565

Rieger, M., \& Gauggel, S. (2002). Inhibition of ongoing responses in patients with traumatic brain injury. Neuropsychologia, 40(1), 76-85. doi: 10.1016/S0028-3932(01)00068-9

Rolls, E. T., Hornak, J., Wade, D., \& McGrath, J. (1994). Emotion-related learning in patients with social and emotional changes associated with frontal lobe damage. Journal of Neurology, Neurosurgery \& Psychiatry, 57(12), 1518-1524. doi: 10.1136/jnnp.57.12.1518

Rylander, G., \& Frey, H. (1939). Personality changes after operations on the frontal lobes: A clinical study of 32 cases: E. Munksgaard; London, H. Milford, Oxford University Press.

Sabaz, M., Simpson, G. K., Walker, A. J., Rogers, J. M., Gillis, I., \& Strettles, B. (2014). Prevalence, comorbidities, and correlates of challenging behavior among communitydwelling adults with severe traumatic brain injury: A multicenter study. The Journal 
of Head Trauma Rehabilitation, 29(2), E19-E30. doi: 10.1097/HTR.0b013e31828dc590 23640541

Saver, J. L., \& Damasio, A. R. (1991). Preserved Access and Processing of Social Knowledge in a Patient with Acquired Sociopathy Due to Ventromedial Frontal Damage. Neuropsychologia, 29(12), 1241-1249. doi: 10.1016/0028-3932(91)90037-9

Senathi-Raja, D., Ponsford, J., \& Schonberger, M. (2010). Impact of age on long-term cognitive function after traumatic brain injury. Neuropsychology, 24(3), pp. doi: $10.1037 / \mathrm{a} 001823920438211$

Simpson, G., Blaszczynski, A., \& Hodgkinson, A. (1999). Sex offending as a psychosocial sequela of traumatic brain injury. The Journal of Head Trauma Rehabilitation, 14(6), 567-580. doi: 10.1097/00001199-199912000-00005 10671702

Sopena, S., Dewar, B.-K., Nannery, R., Teasdale, T. W., \& Wilson, B. (2007). The European Brain Injury Questionnaire (EBIQ) as a reliable outcome measure for use with people with brain injury. Brain Injury, 21(10), 1063-1068.

Starkstein, S. E., \& Robinson, R. G. (1997). Mechanism of disinhibition after brain lesions. Journal of Nervous and Mental Disease, 185(2), 108-114. doi: 10.1097/00005053199702000-00007

Stout, J. C., Ready, R. E., Grace, J., Malloy, P. F., \& Paulsen, J. S. (2003). Factor analysis of the Frontal Systems Behavior Scale (FrSBe). Assessment, 10(1), 79-85. doi: $10.1177 / 1073191102250339$

Stuss, D. T., \& Benson, D. F. (1984). Neuropsychological Studies of the Frontal Lobes. Psychological Bulletin, 95(1), 3-28. doi: 10.1037//0033-2909.95.1.3

Tate, R. L. (1999). Executive dysfunction and characterological changes after traumatic brain injury: Two sides of the same coin? Cortex, 35(1), 39-55. doi: 10.1016/S00109452(08)70784-6 
Tate, R. L., McDonald, S., \& Lulham, J. M. (1998). Incidence of hospital-treated traumatic brain injury in an Australian community. Australian and New Zealand Journal of Public Health, 22(4), 419-423. doi: 10.1111/j.1467-842X.1998.tb01406.x

Teasdale, T. W., Christensen, A.-L., Willmes, K., Deloche, G., Braga, L., Stachowiak, F., ... Leclercq, M. (1997). Subjective experience in brain injured patients and their close relatives: A European Brain Injury Questionnaire study. Brain Injury, 11(8), 543-564.

Thomsen, I. V. (1984). Late outcome of very severe blunt head trauma: a 10-15 year second follow-up. Journal of Neurology, Neurosurgery \& Psychiatry, 47(3), 260-268. doi: 10.1136/jnnp.47.3.260

Tinius, T. P. (2003). The Integrated Visual and Auditory Continuous Performance Test as a neuropsychological measure. Archives of Clinical Neuropsychology, 18(5), 439-454. doi: $10.1016 / \mathrm{S} 0887-6177(02) 00144-0$

Trahan, E., Pepin, M., \& Hopps, S. (2006). Impaired awareness of deficits and treatment adherence among people with traumatic brain injury or spinal cord injury. Journal of Head Trauma Rehabilitation, 21(3), 226-235.

Velligan, D. I., Ritch, J. L., Sui, D., DiCocco, M., \& Huntzinger, C. D. (2002). Frontal Systems Behavior Scale in schizophrenia: relationships with psychiatric symptomatology, cognition and adaptive function. Psychiatry Research, 113(3), 227236.

Votruba, K. L., Rapport, L. J., Vangel, S. J., Jr., Hanks, R. A., Lequerica, A., Whitman, R. D., \& Langenecker, S. (2008). Impulsivity and traumatic brain injury: The relations among behavioral observation, performance measures, and rating scales. The Journal of Head Trauma Rehabilitation, 23(2), 65-73. doi: 10.1097/01.HTR.0000314525.93381.69 18362760 
903

904

905

906

907

908

909

910

911

912

913

914

915

916

917

918

919

920

921

922

923

Warriner, E. M., Rourke, B. P., Velikonja, D., \& Metham, L. (2003). Subtypes of emotional and behavioural sequelae in patients with traumatic brain injury. Journal of Clinical and Experimental Neuropsychology, 25(7), 904-917. doi: 10.1076/jcen.25.7.904.16494

Watts, A. J., \& Douglas, J. M. (2006). Interpreting facial expression and communication competence following severe traumatic brain injury. Aphasiology, 20(8), 707-722. doi: $10.1080 / 02687030500489953$

Winkler, D., Unsworth, C., \& Sloan, S. (2006). Factors that lead to successful community integration following severe traumatic brain injury. The Journal of Head Trauma Rehabilitation, 21(1), 8-21. doi: 10.1097/00001199-200601000-00002

Ylvisaker, M., Turkstra, L. S., \& Coelho, C. (2005). Behavioral and social interventions for individuals with traumatic brain injury: A summary of the research with clinical implications. Seminars in Speech and Language, 26(4), 256-267. doi: 10.1055/s2005-922104 16278797

Zaloshnja, E., Miller, T., Langlois, J. A., \& Selassie, A. W. (2008). Prevalence of Long-Term Disability From Traumatic Brain Injury in the Civilian Population of the United States, 2005. Journal of Head Trauma Rehabilitation, 23(6), 394-400. doi: 10.1097/01.Htr.0000341435.52004.Ac 
Table 1. Description and psychometric properties of informant-report measures suitable for brain injured populations which include measurement of disinhibited behaviour

\begin{tabular}{|c|c|c|c|}
\hline Measure & Description & Scales/Factors & Psychometric Properties \\
\hline $\begin{array}{l}\text { Current Behaviour } \\
\text { Scale } \\
\text { (CBS; Elsass \& } \\
\text { Kinsella, 1987) }\end{array}$ & $\begin{array}{l}\text { The CBS was developed to quantify the } \\
\text { behavioural profile of head-injured patients. } \\
\text { It consists of } 25 \text { items in which bipolar } \\
\text { adjectives are rated on a 7-point scale, with } \\
\text { higher scores indicating greater disturbance. } \\
\text { The subscale 'Loss of Emotional Control' } \\
\text { includes but is not limited to disinhibited } \\
\text { behaviour. }\end{array}$ & $\begin{array}{l}\text { Loss of motivation } \\
\text { Loss of emotional control }\end{array}$ & $\begin{array}{l}\text { Loss of Emotional Control: IC: .80, } \\
\text { TRR: } 83 \\
\text { (Kinsella et al., 1991) }\end{array}$ \\
\hline $\begin{array}{l}\text { Dysexecutive } \\
\text { Questionnaire } \\
\text { (DEX; Burgess et } \\
\text { al., 1998) }\end{array}$ & $\begin{array}{l}\text { The DEX is a rating scale designated to } \\
\text { sample everyday problems commonly } \\
\text { associated with frontal systems dysfunction. } \\
\text { The DEX comprises of } 20 \text { items sampling } \\
\text { four domains: emotional, motivational, } \\
\text { behavioural and cognitive. The DEX has a } \\
\text { self-report and informant-report form. All } \\
\text { items are rates in terms of frequency on a 5- } \\
\text { point scale: } 0 \text { (never), } 1 \text { (occasionally), } 2 \\
\text { (sometimes), } 3 \text { (fairly often), } 4 \text { (very often). }\end{array}$ & $\begin{array}{l}\text { Inhibition } \\
\text { Intentionality } \\
\text { Executive Memory } \\
\text { Positive Affect } \\
\text { Negative Affect }\end{array}$ & $\begin{array}{l}\text { IC: }>.90 \text { in } 4 \text { different types of raters } \\
\text { (Bennet, Ong \& Ponsford, 2005) } \\
\text { IRR: Neuropsychologists and OT } \\
\text { ratings correlated .79 } \\
\text { Construct validity: DEX-Inhibition } \\
\text { correlates with TMT-B (.43), but not } \\
\text { with RBMT (.06) (Burgess et al. 1998) }\end{array}$ \\
\hline $\begin{array}{l}\text { European Brain } \\
\text { Injury } \\
\text { Questionnaire } \\
\text { (EBIQ; Teasdale } \\
\text { et al., 1997) }\end{array}$ & $\begin{array}{l}\text { Originally designed to be used specifically } \\
\text { with people with brain injury and is } \\
\text { comprised of } 63 \text { items relating to wide- } \\
\text { ranging everyday problems experience } \\
\text { 'within the last month'. There are two parallel } \\
\text { forms; a self-report and a relative-report } \\
\text { version. Items have three response } \\
\text { alternatives; problems occurring either 'not at }\end{array}$ & $\begin{array}{l}\text { Somatic } \\
\text { Cognitive } \\
\text { Motivation } \\
\text { Impulsivity } \\
\text { Depression } \\
\text { Isolation } \\
\text { Physical consequences } \\
\text { Communication }\end{array}$ & $\begin{array}{l}\text { TRR: Impulsivity scale } .86 \text { for self- } \\
\text { report and } .76 \text { for informant-report } \\
\text { (Teasdale et al., 1997) } \\
\text { Discriminant validity: Impulsivity scale } \\
\text { was the only scale which did not } \\
\text { discriminate between the brain-injured } \\
\text { and control group (Sopena, Dewar, } \\
\text { Nannery, Teasdale, \& Wilson, 2007) }\end{array}$ \\
\hline
\end{tabular}


Frontal Systems Behaviour Scale (FrsBe; Stout et al., 2003) 46-item rating scale, with three subscales: Apathy, Disinhibition and Executive dysfunction (after frontal systems damage) with self-rating and a family-rating form. The disinhibition subscale measures behaviours such as impulsivity, inappropriateness and childishness.

Iowa Scales of Personality

Change (ISPC Barrash et al., 1997)

Neuropsychology Behaviour and Affect Profile (NBAP; Nelson et al., 1989)
The ISPC assess 26 personality characteristics which may change as the result of neurological disturbance. For each, informants rate 'before' and 'after' which are compared to determine level of change. One of the five factors is 'Interpersonal/Social disturbance', which includes items assessing social inappropriateness, insensitivity, inappropriate affect, lack of insight, inflexibility and aggression. While some of these items assess disinhibition, others are not specific to the construct.

The NBAP is a 106-item questionnaire designed to assess emotional and behavioural changes since acquired brain damage in patient and relative report form. One of the 5 subscales in 'Inappropriateness' defined as "behaviour which in inappropriate to the context in which it is occurring or to an outside event" scored both "before" (injury) and "now".

\section{Apathy}

\section{Disinhibition}

Executive functioning
IC: family-form : .80, self-form: .75

(Grace and Malloy, 2001)

IRR: . 79 - .92 for subscales (Velligan et al., 2002)

TRR: .78 (Velligan et al., 2002)

Discriminant validity: Total score differentiated a group with frontal lesions from those with non-frontal lesions and controls (Grace, Stout, \& Malloy, 1999)

Executive/Decision-making deficits IRR: .86

\section{Disturbed social behaviour}

Irascibility

Diminished motivation

Distress

Indifference

\section{Inappropriateness}

Pragnosia

Depression

Mania
Discriminant validity: Ventromedial patients showed greater change on 10 of the subscales compared with 50 patients with focal damage elsewhere (Barrash, Anderson, Jones, \& Tranel, 1997)
Inappropriateness: IC: .59 for 'before' responses and .81 for 'now' responses, TRR: .92 for 'now' responses (Nelson et al., 1989)

Discriminant validity: Clinic referred TBI patients rated as more inappropriate compared to non-referred patients (Nelson et al., 1998) 
Neuropsychiatric Inventory

(NPI; Cummings

et al., 1994)

Overt Behaviour

Scale

(OBS Kelly et al.,

2006)

Designed for dementia patients and now validated for TBI. Interview format with clinician interviewing an informed caregiver. Assesses 12 domains, including

'Disinhibition'. Presence or absence of seven disinhibited behaviours and their frequency and severity is assessed along with the level of distress they cause the informant.

Clinician rating scale designed to measure common challenging behaviors after acquired brain injury. The OBS contains nine categories, two of which measure socially disinhibition behaviour. Hierarchical levels within the categories represent increasing severity.
Delusions

Hallucinations

Agitation/Aggression

Depression/Dysphoria

Anxiety

Elation/Euphoria

Apathy/Indifference

Disinhibition

Irritability/Lability

Aberrant motor behavior

\section{Aggression}

Inappropriate sexual behaviour

Perseveration/repetition

Wandering/absconding

Inappropriate social behaviour

Lack of initiation
Disinhibition: IC: 88 , IRR: $93.6 \%$ to $100 \%$ for different behaviours, TRR: .79 for frequency scores and .86 for severity scores

Content validity: Panel of experts rated behaviours as being 'well-assessed' by the items (Cummings, 1997; Cummings et al., 1994)

IRR: .97 for OBS total score

TRR: .77

Convergent validity: OBS total levels correlated with 'social behaviour' on the Portland Adaptability Inventory (.49) and loss of emotional control on the CBS (.66) (Kelly et al., 2006)

Note: $\mathrm{IC}=$ Internal consistency, $\mathrm{IRR}=$ Interrater-reliability, $\mathrm{TRR}=$ test-retest reliability, TMT-B=Trail Making Test-B, RMBT=Rivermead Behavioural Memory Test 
Table 2. Summary of studies investigating the prevalence of socially disinhibited behaviour after TBI

\begin{tabular}{|c|c|c|c|c|c|c|c|}
\hline Study & Sample Type & Sample Size & $\begin{array}{l}\text { Mean age } \\
\text { (SD) }\end{array}$ & Injury Severity & Variable Name & Measure Used & $\begin{array}{c}\text { Rate of social } \\
\text { disinhibition }\end{array}$ \\
\hline $\begin{array}{l}\text { Lezak \& O’Brien } \\
\text { (1988) }\end{array}$ & Unselected & 42 & $27.1(7.4)$ & $\begin{array}{l}\text { Moderate - } \\
\text { severe }\end{array}$ & $\begin{array}{l}\text { Appropriate Social } \\
\text { Interaction }\end{array}$ & PAI & $\begin{array}{l}31-73 \% \text { across } 6 \text { time } \\
\text { points (up to } 60 \\
\text { months post injury) }\end{array}$ \\
\hline $\begin{array}{l}\text { Ponsford et al. } \\
\text { (1995) }\end{array}$ & Unselected & 175 & $27.4(11.9)$ & $\begin{array}{l}\text { Severe } \\
\text { Mean PTA: } 45.9 \\
\text { days }\end{array}$ & $\begin{array}{l}\text { Inappropriate } \\
\text { Social Behaviour }\end{array}$ & $\begin{array}{l}\text { Self-report yes/no } \\
\text { question }\end{array}$ & $26 \%$ \\
\hline $\begin{array}{l}\text { Johnson \& Balleny } \\
\text { (1996) }\end{array}$ & Unselected & 46 & $30.4(14.15)$ & $\begin{array}{l}\text { Severe } \\
\text { Mean PTA: } 13.0 \\
\text { days }\end{array}$ & Disinhibition & $\begin{array}{l}\text { Author developed } \\
\text { questionnaire }\end{array}$ & $\begin{array}{l}47 \% \text { of those that } \\
\text { were }<18 \text { months } \\
\text { since injury } \\
44 \% \text { of those that } \\
\text { were }>18 \text { months } \\
\text { since injury }\end{array}$ \\
\hline $\begin{array}{l}\text { Cantagallo \& } \\
\text { Dimarco (2002) }\end{array}$ & Unselected & 53 & $32.9(13.4)$ & $\begin{array}{l}\text { Severe } \\
\text { Mean PTA: } 14.8 \\
\text { weeks }\end{array}$ & Disinhibition & NPI & $22.6 \%$ \\
\hline $\begin{array}{l}\text { Warriner et al. } \\
(2003)\end{array}$ & Unselected & 300 & $35(12.5)$ & Mild - moderate & $\begin{array}{l}\text { Externalising } \\
\text { Subtype }\end{array}$ & MMPI & $13 \%$ \\
\hline Kelly et al. (2008) & $\begin{array}{l}\text { Referred for } \\
\text { challenging } \\
\text { behaviours }\end{array}$ & 190 & $36.5(14.3)$ & $\begin{array}{l}\text { Mild - severe on } \\
\text { the Disability } \\
\text { Rating Scale }\end{array}$ & $\begin{array}{l}\text { Inappropriate } \\
\text { Social Behaviour }\end{array}$ & OBS & $85.8 \%$ \\
\hline Ciurli et al. (2011) & Unselected & 120 & $31.3(12.7)$ & Severe & Disinhibition & NPI & $28 \%$ \\
\hline $\begin{array}{l}\text { Monsalve et al. } \\
\text { (2012) }\end{array}$ & Unselected & 53 & $35(14.2)$ & Severe & Disinhibition & NPI & $32.1 \%$ \\
\hline Sabaz et al. (2014) & Unselected & 507 & $\begin{array}{l}\text { Mean not } \\
\text { reported }\end{array}$ & Severe & $\begin{array}{l}\text { Inappropriate } \\
\text { Social Behaviour }\end{array}$ & OBS & $33 \%$ \\
\hline
\end{tabular}

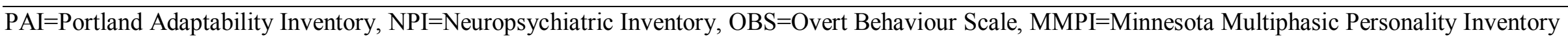


Table 3. Summary of studies investigating the relationships between inhibitory control measures and social disinhibition measures after TBI

\begin{tabular}{lccccc}
\hline Study & $\begin{array}{c}\text { Sample } \\
\text { Size }\end{array}$ & Injury Severity & $\begin{array}{c}\text { Inhibitory control } \\
\text { measure }\end{array}$ & \multicolumn{1}{c}{$\begin{array}{c}\text { Outcome Variable } \\
\text { Relationship } \\
\text { reported? }\end{array}$} \\
\hline Tate (1999) & 30 & $\begin{array}{l}\text { Severe } \\
\text { Mean PTA 59.59 } \\
\text { days (SD=51.05) } \\
\text { Severe }\end{array}$ & Errors on fluency test & Loss of emotional control (CBS) \\
$\begin{array}{l}\text { Osborne-Crowley et al. } \\
(2015)\end{array}$ & 22 & $\begin{array}{l}\text { Mean PTA 64.57 } \\
\text { days (SD=46.52) }\end{array}$ & Errors on fluency test & Informant-reported disinhibition (NPI) \\
$\begin{array}{l}\text { Osborne-Crowley et al. } \\
(2015)\end{array}$ & 22 & $\begin{array}{l}\text { Severe } \\
\text { Mean PTA 64.57 } \\
\text { days (SD=46.52) } \\
\text { Moderate-Severe }\end{array}$ & Errors on fluency test & $\begin{array}{l}\text { Laboratory observed social } \\
\text { disinhibition }\end{array}$ \\
$\begin{array}{l}\text { Lipszyc et al. (2014) } \\
\text { children }\end{array}$ & $\begin{array}{l}\text { Stop-Signal task } \\
\text { Severe } \\
\text { Mean 24.6 days } \\
\text { (SD=17.4) }\end{array}$ & Go/No-Go & $\begin{array}{l}\text { Laboratory observed social } \\
\text { disinhibition }\end{array}$ \\
\hline
\end{tabular}

$\overline{\mathrm{CBS}}=$ Current Behaviour Scale, NPI=Neuropsychiatric Inventory, BRIEF= Behavior Rating Inventory of Executive Function 
Table 4. Summary of studies investigating the outcomes associated with disinhibited behaviour after TBI

\begin{tabular}{|c|c|c|c|c|}
\hline Study & Sample Size & Injury Severity & Disinhibition Variable & Outcome Variable \\
\hline Brooks \& McKinlay (1983) & $\begin{array}{l}55 \text { people with } \\
\text { TBI and their }\end{array}$ & $\begin{array}{l}\text { Severe } \\
\text { PTA at least } 48 \text { hours }\end{array}$ & Immaturity, Insensitivity & $\begin{array}{l}\text { Caregiver burden (7-point rating } \\
\text { scale of 'strain' felt) }\end{array}$ \\
\hline Groom et al (1998) & $\begin{array}{c}153 \text { family } \\
\text { members of } \\
\text { person with TBI }\end{array}$ & $\begin{array}{l}\text { Severe } \\
\text { Mean PTA } 94.8 \text { days } \\
\text { SD }=128.5\end{array}$ & Inappropriateness (NBAP) & $\begin{array}{l}\text { Family functioning (FAD-GF) } \\
\text { Caregiver stress (PSS) }\end{array}$ \\
\hline Winkler et al. (2014) & $\begin{array}{l}40 \text { people with } \\
\text { TBI }\end{array}$ & $\begin{array}{l}\text { Severe } \\
\text { PTA at least } 3 \text { weeks }\end{array}$ & Loss of emotional control (CBS) & $\begin{array}{l}\text { Low/high community integration } \\
\text { (CIQ, CIM, SPRS) }\end{array}$ \\
\hline Juengst et al. (2014) & $\begin{array}{l}74 \text { people with } \\
\text { TBI }\end{array}$ & Moderate-Severe & Disinhibition (FrSBe) & Suicidal endorsement (PHQ) \\
\hline Simpson et al. (1999) & $\begin{array}{l}29 \text { males with } \\
\text { TBI who had } \\
\text { aberrant sexual } \\
\text { behaviours }\end{array}$ & $\begin{array}{l}\text { Severe } \\
\text { PTA } 84 \text { days } \\
\mathrm{SD}=59.42\end{array}$ & $\begin{array}{l}\text { Inappropriate sexual behaviours } \\
\text { (Assessment by staff members } \\
\text { of rehabilitation centre) }\end{array}$ & Legal problems (criminal charges) \\
\hline
\end{tabular}

